\title{
Metachronic Pancreatic Metastasis of Renal Clear Cell Carcinoma
}

\author{
I. Ben Moula ${ }^{*}$, R.Chaouachi, N.Chikhaoui, O.Kacimi, N.Touil, A.Siwane, H.Tabakh
}

Emergency Department of Radiology, Ibn Rochd University Hospital, Casablanca, Morocco

DOI: $10.36347 /$ sjmcr.2020.v08i07.004

| Received: 27.03.2020 | Accepted: 03.04.2020 | Published: 16.07.2020

*Corresponding author: Ben Moula Imen

\section{Abstract}

Pancreatic metastases from kidney cancer are rare and generally late onset. They are most often detected by an abdominal computed tomography performed as part of kidney cancer surveillance. We report the observation of a 50year-old diabetic patient who had a nephrectomy for a clear cell renal adenocarcinoma seven years ago, during followup, abdominal CT and nuclear magnetic resonance imaging (MRI) revealed two heterogeneous pancreatic nodules, the kinetics of enhancement resembles that of the primary tumor, and pathology has in fact revealed metachronic pancreatic metastases of his clear cell renal adenocarcinoma.

Keywords: Pancreatic metastases, kidney cancer, imaging.

Copyright @ 2020: This is an open-access article distributed under the terms of the Creative Commons Attribution license which permits unrestricted use, distribution, and reproduction in any medium for non-commercial use (NonCommercial, or CC-BY-NC) provided the original author and source are credited.

\section{INTRODUCTION}

The secondary locations of renal clear cell carcinomas are most often pulmonary, hepatic or bone. Pancreatic locations are exceptional and represent, depending on the series, 2 to $4 \%$ of pancreatic malignant lesions. We report the observation of a pancreatic tumor secondary to a renal clear cell adenocarcinoma which appeared seven years after nephrectomy.

\section{OBSERVATION}

This is a 50-year-old diabetic (type II) patient who had seen for gross macroscopic hematuria that had been progressing for a week. An emergency ultrasound followed by an abdominal computed tomography (CT) revealed a tissue mass of $50 \mathrm{~mm}$ at the expense of the lower pole of the right kidney. The extension assessment, including chest $\mathrm{CT}$ and bone scan, was negative.

An enlarged right nephrectomy was performed. Pathology has confirmed the presence of a clear cell renal adenocarcinoma with invasion of perirenal fat and neoplastic thrombus in the right renal vein performing a pT3N0 stage according to the TNM classification. Seven years later, during follow-up, abdominal CT and nuclear magnetic resonance imaging (MRI) revealed two heterogeneous pancreatic nodules. One was $14 \mathrm{~mm}$ and was in the isthmic position (Figure 1), the other was $20 \mathrm{~mm}$ and was located in the more caudal position (Figure 2). The hypervascular character of these nodules immediately oriented towards metastases of his kidney cancer more than towards a primary pancreatic tumor. The patient then benefited from a splenopancreatectomy enlarged to the isthmus to perform the excision of these two nodules. Pathology has in fact revealed three pancreatic metastases of his clear cell adenocarcinoma. Three months later, an abdominal CT scan showed a $20 \mathrm{~mm}$ nodule in the incinatus process which had not been detected until now. The patient benefited from a totalization of his pancreatectomy to perform the removal of this nodule which was also a metastasis of his kidney cancer. Postoperative follow-ups were simple and insulin therapy was started. Three years after his pancreatectomy, the patient was in good general condition and free from any tumor recurrence.

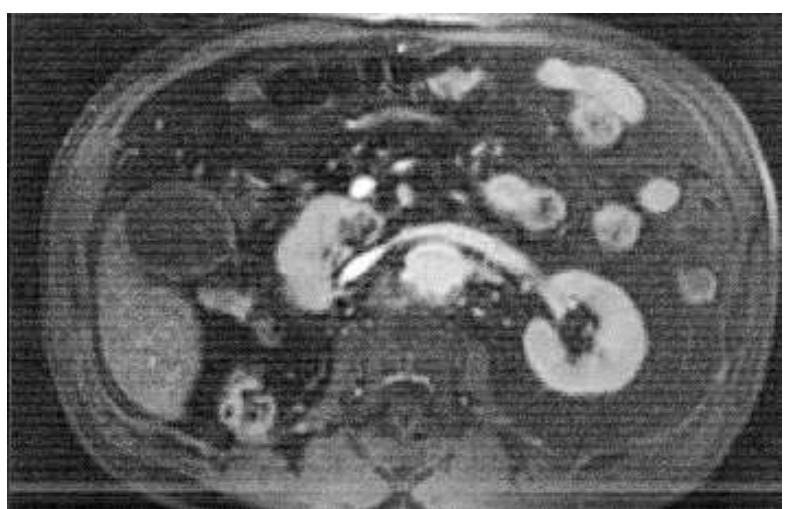

Fig- 1: Abdominal MRI. T1 acquisition after Gadolinium injection. Cross section through the head of the pancreas. The hypervascular metastasis is well visualized at the level of the incinatus process 


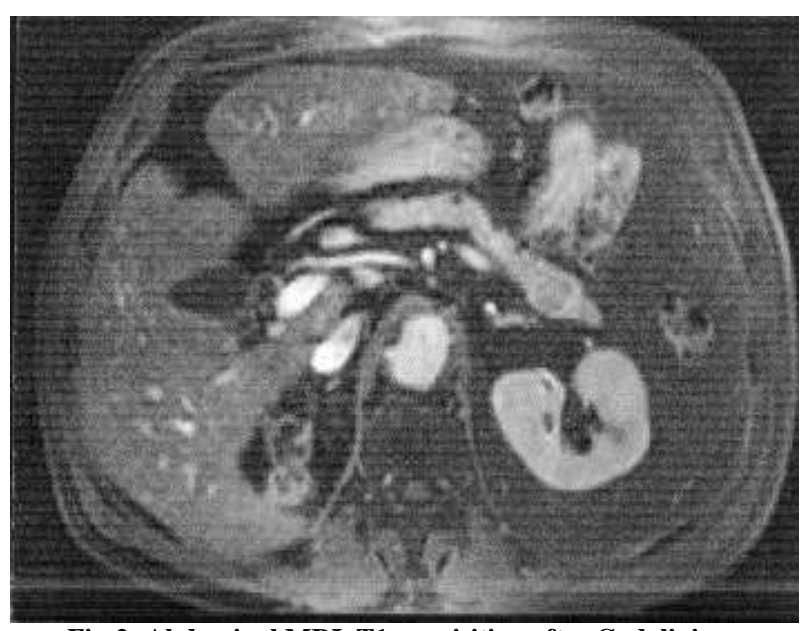

Fig-2: Abdominal MRI. T1 acquisition after Gadolinium injection. Cross section through the tail of the pancreas. Metastasis is well visualized

\section{DISCUSSION}

Pancreatic metastases from kidney cancer are rare and appear late. Very few cases have been reported in the literature $[1,3,4,8,11,12]$. The sex ratio is 1.7 with a male predilection, which can be superimposed on that of the epidemiology of kidney cancer [9]. At diagnosis, the average age is 61 years with extremes ranging from 39 to 76 years in the literature [9]. The average delay between nephrectomy and the appearance of metastases is long with an average of 10 years but they can appear earlier or even syynchronous with the primary renal tumor.

The clinical manifestations of pancreatic metastases are not very specific [7]. They can reveal themselves by abdominal pain, a table of deterioration of the general state with slimming, an exocrine or endocrine pancreatic insufficiency, an acute pancreatitis even a compression of vicinity (stomach, vessels, and duodenum) responsible for digestive hemorrhage. However, due to their slow growth, metastases are often asymptomatic and therefore discovered incidentally in the context of surveillance [11].

Abdominal ultrasound hardly explores the pancreatic gland and has no specificity for the diagnosis of secondary lesions; the lesions appear in the form of hypoechogenic solid masses located in the pancreatic parenchyma [3]. Doppler ultrasound has a better sensitivity since it will highlight the hypervascular character of the lesion [2]. The abdominal CT shows a well circumscribed mass which is iso or hypodense compared to the normal pancreas on the sections without contrast. Enhancement is generally heterogeneous, but tends to be homogeneous in small lesions and peripheral in larger lesions, probably due to central necrosis, in general, the kinetics of enhancement resembles that of the primary tumor [2-4]. Calcifications are rare and pancreatic duct obstruction is common for lesions of the head and body, seen in about $40 \%$ of cases, and can be associated with obstruction of the main bile duct and intrahepatic biliary dilation. The hypervascularized nature of these metastases manifests itself in the stereotypes by a lesion which takes the contrast unlike the primary tumors of the pancreas, which are hypovascularized $[2,3,5]$.

However, the puncture is justified if no primary tumor is known, if the appearance of the pancreatic lesion suggests another histology (in the case of a hypervascular pancreatic mass, the main differential diagnosis is that of endocrine tumor) or if the lesion $\mathrm{n}$ is not resectable in order to obtain histological evidence of the pancreatic lesion $[7,11$, 13].

Secondary pancreatic locations for kidney cancer appear to be of lymphatic origin. Indeed, a study carried out by Nagakawa by injection of radiolabelled carbon in patients with cancer of the head of the pancreas shows that the lymph node extension extends to behind the renal arteries [10]. Thus, a lymph node invasion along the renal pedicle can explain the pancreatic involvement. Another possible mode of spread is the hematogenous pathway. The existence of arteriovenous shunts within the tumor of the kidney leads to a decrease in vascular resistance with as a consequence an ectasia of the peri-tumoral and perirenal drainage veins. The venous pressure in this exorenal system being higher than that of the adjacent structures, large anastomoses are created with the adrenal veins and the portal system. Thus and especially if there is a thrombosis of the renal vein, neoplastic emboli can migrate in a reno-portal shunt [9].

The treatment of pancreatic metastases is surgical [12]. Pancreatic resection is most often major, the type of which depends on the topography of the lesion $[6,11]$. A cephalic duodenopancreatectomy or a splenopancreatectomy are most often necessary [13]. Hernandez reports the case of a patient who underwent a laparoscopic caudal pancreatectomy in this indication [5]. The multiple and diffuse nature of secondary pancreatic lesions can lead to total pancreatectomy as is the case in our observation. Some authors opt for a pancreatic resection limited to the tumor by performing atypical pancreatectomies in order to preserve as much as possible the healthy parenchyma under cover of an extemporaneous examination of the section sections [16]. This attitude does not prevent the occurrence of pancreatic fistula and does not seem to modify either the frequency of recurrences or the survival of patients $[11,16]$.

Chemotherapy with vinblastine or immunotherapy with interferon alpha have not proven to be effective in the treatment of pancreatic metastases of kidney tumors, but they may nevertheless be useful after excisional surgery with lymph node involvement or minimal tumor residue $[11,15]$. 
Survival after surgical resection of pancreatic metastases is satisfactory with a median survival of 30 months. For Tuech, the 5-year survival rate is $31 \%$ in the case of metastases localized only to the pancreas $[14,17]$.

The good prognostic factors for these pancreatic metastases appear to be the late onset of a pancreatic location, an asymptomatic form, a single pancreatic lesion or a radiological appearance of central necrosis of the tumor lesion [11].

\section{Conclusion}

Pancreatic metastases from kidney cancer are rare and generally late onset. They are most often detected by an abdominal computed tomography performed as part of kidney cancer surveillance. Early diagnosis makes it possible to attempt a curative surgical gesture (pancreatic resection adapted to tumor location) which seems to be the only treatment capable of prolonging the survival of patients.

\section{REFERENCES}

1. Faure JP, Tuech JJ, Richer JP, Pessaux P, Arnaud JP, carretier M. Pancreatic metastasis of renal cell carcinoma: presentation, treatment and survival. The Journal of urology. 2001 Jan 1;165(1):20-2.

2. Flath B, Rickes S, Schweigert $M$, Lochs $H$, Possinger K, Wermke W. Differentiation of a pancreatic metastasis of a renal cell carcinoma from a primary pancreatic carcinoma by echoenhanced power Doppler sonography. Pancreatology. 2003;3(4):349-51.

3. Ghavamian R, Klein KA, Stephens DH, Welch TJ, Leroy AJ, Richardson RL, Burch PA, Zincke H. Renal cell carcinoma metastatic to the pancreas: clinical and radiological features. InMayo Clinic Proceedings 2000 Jun 1 (Vol. 75, No. 6, pp. 581585). Elsevier.

4. Hashimoto M, Watanabe G, Matsuda M, Dohi T, Tsurumaru M. Management of the pancreatic metastases from renal cell carcinoma: report of four resected cases. Hepato-gastroenterology. 1998;45(22):1150-4.

5. Hernandez DJ, Kavoussi LR, Ellison LM. Laparoscopic distal pancreatectomy for metastatic renal cell carcinoma. Urology. 2003 Sep 1;62(3):551.

6. Hirota $\mathrm{T}$, Tomida $\mathrm{T}$, Iwasa $\mathrm{M}$, Takahashi $\mathrm{K}$, Kaneda M, Tamaki H. Solitary pancreatic metastasis occurring eight years after nephrectomy for renal cell carcinoma. International journal of pancreatology. 1996 Apr 1;19(2):145-53.

7. Kassabian A, Stein J, Jabbour N, Parsa K, Skinner D, Parekh D, Cosenza C, Selby R. Renal cell carcinoma metastatic to the pancreas: a singleinstitution series and review of the literature. Urology. 2000 Aug 1;56(2):211-5.

8. Law CH, Wei AC, Hanna SS, Al-Zahrani M, Taylor BR, Greig PD, Langer B, Gallinger S. Pancreatic resection for metastatic renal cell carcinoma: presentation, treatment, and outcome. Annals of surgical oncology. 2003 Sep 1;10(8):922-6.

9. Masson J, Bereder I, Ragni E, MASSON JC, Richaud C. Cancer du rein et métastases pancréatiques. A propos de 3 cas. Progrès en urologie (Paris). 1996;6(3):443-6.

10. Nagakawa $T$, Kobayashi $H$, Ueno $K$, Ohta $T$, Kayahara M, Miyazaki I. Clinical study of lymphatic flow to the paraaortic lymph nodes in carcinoma of the head of the pancreas. Cancer. 1994 Feb 15;73(4):1155-62.

11. Peschaud F, Cheynel N, Hagry O, Tremeaux JC, Rat P, Favre JP. Surgical treatment of pancreatic metastases from renal carcinoma. InAnnales de chirurgie 2002 Sep (Vol. 127, No. 7, pp. 527-531).

12. Rivoire M, Voiglio EJ. Late pancreatic metastases from renal cell carcinoma. Surgery. 1996 Feb $1 ; 119(2): 240$.

13. Robbins EG, Franceschi D, Barkin JS. Solitary metastatic tumors to the pancreas: a case report and review of the literature. American Journal of Gastroenterology. 1996 Nov 1;91(11).

14. Sahin M, Foulis AA, Poon FW, Imrie CW. Late focal pancreatic metastasis of renal cell carcinoma. Digestive surgery. 1998;15(1):72-4.

15. Sohn TA, Yeo CJ, Cameron JL, Nakeeb A, Lillemoe KD. Renal cell carcinoma metastatic to the pancreas: results of surgical management. Journal of Gastrointestinal Surgery. 2001 Aug $1 ; 5(4): 346-51$.

16. Stankard CE, Karl RC. The treatment of isolated pancreatic metastases from renal cell carcinoma: a surgical review. American Journal of Gastroenterology. 1992 Nov 1;87(11).

17. Tuech JJ, Pessaux P, Chautard D, Rouge C, Binelli C, Bergamaschi R, Arnaud JP. Results of duodenopancreatectomy for solitary pancreatic metastasis from renal cell carcinoma. Journal of hepato-biliary-pancreatic surgery. 1999 Dec 1;6(4):396-8. 